\title{
Wittgenstein y la teoría contemplativa del significado. Observaciones a la tesis de Juan Abugattás ${ }^{1}$
}

\author{
Álvaro Revolledo Novoa \\ Universidad Nacional Mayor de San Marcos \\ alvarorevolledo@gmail.com
}

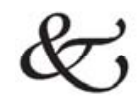

Resumen

Este artículo consiste en una lectura crítica de la interpretación que realiza el filósofo peruano Juan Abugattás en torno a la "teoría contemplativa” del Tractatus Logico Philosophicus (TLP) de Ludwig Wittgenstein. En particular, se encarga de revisar la tesis de Bachiller de Juan Abugattás en la que afirma que la teoría del significado del TLP es reemplazada por la teoría del uso en la obra posterior de Wittgenstein. El objetivo central de este artículo es demostrar que la teoría del significado del TLP no es, como pretende Abugattás, una mera teoría contemplativa, y que la teoría del significado de las Philosophische Bemerkungen (Ph. B.), a diferencia de lo que sostiene Abugattás, aun mantiene intacta la perspectiva del $T L P$ respecto de cómo el lenguaje puede permitirnos conocer el mundo. En ambos casos, sostengo que la teoría del significado del TLP obedece a una respuesta a la crítica linguiística de Mauthner y sus consecuencias en el plano del conocimiento.

Palabras claves: Wittgenstein, teoría del significado, Tractatus Logico Philosophicus, lenguaje, conocimiento.

\footnotetext{
Abstract

This paper consists in a critical lecture on Peruvian philosopher Juan Abugattás's interpretation about "contemplative theory" from Tractatus

1 Ponencia presentada en el conversatorio Wittgenstein entre nosotros. Observaciones a las investigaciones filosóficas sobre Wittgenstein en San Marcos, organizado en el Seminario de los Viernes Filosóficos, Universidad Nacional Mayor de San Marcos, Auditorio de la Facultad de Letras y Ciencias Humanas, 12 de noviembre de 2010.
} 
Logico Philosophicus (TLP) by Ludwig Wittgenstein. Particularly, it is responsible for reviewing Abugattás's bachelor thesis where he says that the Tractatus's theory of meaning is replace with the use theory of meaning in later Wittgenstein's work. The central purpose of this essay is to demonstrate that the Tractatus's theory of meaning is not a simple "contemplative theory" like Abugattás say, and also that the theory of meaning of Philosophische Bemerkungen (Ph. B.) still keeps the Tractatus 's point about how we can use the language to know the world. In both cases, I maintain that the Tractatus's theory of meaning try to be a response to linguistic critic from Mauthner and its consequences in knowledge aspect.

Key words: Wittgenstein, Theory of meaning, Tractatus Logico Philosophicus, Language, Knowledge.

\section{Introducción}

La recepción crítica de problemas y tradiciones de discusión heredados de la filosofía occidental ha constituido una de las fórmulas más comunes en que se ha desarrollado el filosofar en nuestro país. En el caso particular de la tradición sanmarquina, y desde una perspectiva analítica, el pensamiento filosófico de Ludwig Wittgenstein y sus implicancias constituye un claro ejemplo de ello. Salazar Bondy ${ }^{2}$, Abugattás, Ballón ${ }^{3}$, son algunos de los nombres de filósofos sanmarquinos que contribuyeron a cimentar una relativa continuidad en la investigación filosófica en torno a la obra de Wittgenstein, ya sea replanteando sus alcances filosóficos bajo una nueva interpretación, analizando creativamente alguna de sus categorías filosóficas o señalando sus inconsistencias teóricas desde modelos alternativos. En los últimos años, nuevas tesis de grado se han presentado en esta misma dirección, y todo parece indicar que las discusiones continuarán con el propósito de enriquecer el debate. Es este el marco de referencia que nos invita a pensar y escribir al respecto, pero sobre todo, porque conforman nuestra tradición de discusión, la misma que se mantiene viva y abierta, y de cuyo examen podremos tentativamente avizorar hacia dónde nos conduce.

El objeto de nuestro artículo es una tesis particularmente interesante. Al leerla detenidamente encontramos no solo un modelo de investigación

2 Me he dedicado a analizar las implicancias filosóficas de los ensayos de Salazar Bondy sobre la filosofía de L. Wittgenstein en mi ensayo "Wittgenstein y la metafísica. Observaciones a la interpretación de Salazar Bondy".

3 Aunque muy brevemente, he adelantado algunas de mis opiniones respecto de la tesis de licenciatura de José Carlos Ballón titulada Wittgenstein y la teoría del conocimiento (Lima, 1983) en mi ensayo "Cómo trazar figuras en la arena. Acerca de "mundo" y "realidad" en el Tractatus de Wittgenstein". 
filosófica debido a la profundidad y sagacidad expuestas ${ }^{4}$, sino un texto bellamente escrito en tono de reflexión personal, en el que su joven autor ${ }^{5}$ no duda en señalar sus críticas a filósofos connotados, llegando, incluso, a ponerlos en ridículo ${ }^{6}$, y en el que ha dejado escritas algunas sentencias dignas de convertirse en lapidarias ${ }^{7}$. Me refiero a la tesis de bachiller del maestro Juan Abugattás Abugattás, una investigación pionera entre los estudios sobre el segundo Wittgenstein sustentada el año 1972 bajo el título El concepto de análisis en la Segunda Filosofía de L. Wittgenstein. Dicha investigación, con una extensión de 95 páginas mecanografiadas, está dividida en tres capítulos: Capítulo I El hablante como insensato, Capítulo II La "Imago-mundi” y Capítulo III Reflexiones sobre el método. Aunque son varias las afirmaciones polémicas que sostiene Abugattás en esta tesis, nuestro abordaje estará centrado en el primer capítulo, específicamente en lo que Abugattás denomina "Teorías contemplativas del significado" y de manera particular en la forma cómo Abugattás analiza, desde esa perspectiva, el Tractatus Logico Philosophicus (TLP). Mi discusión con Abugattás girará entonces a propósito de dos observaciones centrales: demostrar que la teoría del significado del TLP no es, como pretende Abugattás, una mera teoría contemplativa, y que la teoría del significado de las Philosophische Bemerkungen (Ph. B.), a diferencia de lo que sostiene Abugattás, aun mantiene intacta la perspectiva del TLP respecto de cómo el lenguaje puede permitirnos conocer el mundo. Procuraré desarrollar estas dos observaciones a la luz de una tercera que servirá de eje: que el TLP de Wittgenstein no suscribe

4 Ésta ha sido la razón principal por la que nos animamos a considerarla una de las mejores tesis en filosofía en San Marcos, sino la mejor. Personalmente, mi motivación al redactar el presente ensayo ha sido la de rendir un homenaje filosófico al gran maestro, quien me enseñara en el Seminario de Kant y en la cátedra de Filosofía de la psicología en mis estudios de pregrado en San Marcos.

5 El año en que sustenta su tesis de bachiller Juan Abugattás tenía 24 años de edad.

6 Es el caso de John Austin, a quien Abugattás critica el haber "instrumentalizado groseramente la filosofía de Wittgenstein", convirtiéndola en un "quehacer trivial" a través de una especie de "sicosis clasificatoria”. Dice Abugattás: "Estos herbolarios metidos a filósofos, uno de cuyos más logrados paradigmas es, sin duda, John Austin, justifican, en cierto modo, las críticas recientes hechas a la filosofía analítica" (Abugattás 1972, p. 43). Tras citar un párrafo de A plea for excuses de Austin, en que, según Abugattás, "sostiene Austin que el mejor modo de resolver los problemas filosóficos es evitar enfrentarlos cara a cara y que es una admirable muestra de prudencia y buen gusto el irse por las ramas" (Abugattás 1972, p. 44), Abugattás concluye: "Lo malo de esta posición no es, evidentemente, que se recomiende la utilización del método analítico; lo malo es que se inste a utilizarlo para ventilar banalidades. Cuántos y cuáles sean los modos de pedir disculpas, es algo que debe interesar más a un individuo que quiera perfeccionar el manual de Carreño, que a un filósofo" (Abugattás 1972, p. 45).

7 Una de mis favoritas, es respecto del valor de la imaginación en la investigación filosófica. Dice Abugattás: "Cuando en el futuro se trate de explicar la gran vitalidad del pensamiento filosófico contemporáneo, se encontrará, seguramente, que la clave de todo está en la irrupción de la "imaginación” como el instrumento más valioso de la reflexión filosófica” (Abugattás 1972, p. 80).

LETRAS 81 (116), 2010 
una teoría del significado que flota en el aire, sino que obedece a una respuesta a la crítica linguiística de Mauthner y sus consecuencias respecto del plano del conocimiento, considerando siempre la forma cómo se relacionan el lenguaje y el mundo.

\section{La crítica a la teoría "contemplativa" del significado en el TLP}

Aunque la tesis de Abugattás discute propiamente la naturaleza del método analítico y su ocurrencia según una concepción del mundo en los marcos de la teoría del uso en el segundo Wittgenstein ${ }^{8}$, como lo indiqué al inicio, me concentraré básicamente en las afirmaciones respecto de la teoría del significado en el TLP descritas en el Capítulo I de esta tesis, en vista de que son relevantes para la presente discusión, y porque constituyen elementos importantes de la argumentación de Abugattás de los cuales se sigue, en buena cuenta, su apuesta por la teoría del uso.

El problema que vamos a discutir es el problema del significado, el mismo que, según Abugattás, tendría por lo menos dos formulaciones posibles. En la primera forma el problema se enuncia con la pregunta: ¿cómo es que una cosa es (puede ser) signo de otra? Ésta es la formulación común a Russell y Tarski, en la que el signo aparece como una representación, y en la cual se asume la relación entre palabra (sonidos) y cosas (objetos) que ella refiere. La segunda formulación considera que la palabra no es signo del objeto sino símbolo de las afecciones del alma causadas por los objetos. Es la formulación de Aristóteles, Locke y Saussure, en que se introduce el "concepto" o "idea" como un nuevo factor.

Según Abugattás, ya sea que el problema se aborde de la primera o segunda forma, existen por lo general cuatro respuestas a la pregunta ¿qué es el significado? La primera entiende el significado como la palabra, mientras que una segunda lo identifica con la cosa u objeto mentado. La dificultad de estas dos primeras respuestas es que aluden a entes físicos, los mismos que, al ser contingentes, conducirían a la creencia de que el significado sería igualmente contingente. La tercera respuesta entiende el significado como el concepto y la cuarta como la proposición. Obviamente, lo que importa en el análisis de Abugattás es concentrarse en esta cuarta respuesta para ver "cómo formuló Wittgenstein su primera teoría del significado, a fin de comprender luego el sentido de la crítica a que posteriormente la sometió” (Abugattás 1972, p. 3).

8 La tesis como tal de Abugattás se puede sintetizar en dos afirmaciones centrales: i) El método analítico ocurre en el interior o desde una concepción del mundo que puede denominarse "idealismo lingüístico", el mismo que es consecuencia de la teoría del uso; y ii) el concepto "forma de vida" es el hilo conductor que permite recorrer toda la obra de Wittgenstein dándole coherencia (y cohesión). 
Con el fin de no excederme innecesariamente con las referencias textuales y con el ánimo de presentar claramente nuestra exposición, en lo que sigue haré una reconstrucción racional de la interpretación que hace Abugattás de la teoría del significado del TLP:

i. La proposición es una "imagen" de la realidad (una proposición es tal solo si "representa").

ii. "Representar" es reproducir las relaciones que se establecen entre los elementos de la realidad (los objetos). El nombre "representa" al objeto en la proposición; el nombre es el significado del objeto (no es una vuelta al "realismo").

iii. Los objetos son las sustancia del mundo; pero existen en su relación con otros objetos (en Estados de cosas).

iv. Un objeto fuera de un estado de cosas carece de toda propiedad material.

v. La proposición asigna propiedades materiales al objeto. La proposición más simple tiene la forma $\mathrm{F}(\mathrm{x})$ (" $\mathrm{F}$ " designa una propiedad material; $\mathrm{F}(\mathrm{x})$ es un estado de cosas).

vi. Un estado de cosas y una proposición son lo mismo, en virtud de su misma estructura lógica.

vii. "Representar" es compartir la misma estructura lógica con un estado de cosas.

viii. Las proposiciones propiamente dichas son las de la ciencia natural, porque la función descriptiva del lenguaje es la única que importa (para reproducir la realidad).

ix. La verdad consiste en la reproducción correcta de la realidad.

$x$. Un signo proposicional que no cumple con esto (que no reproduce) es una proposición falsa, o una pseudo proposición carente de sentido.

De las afirmaciones señaladas importan para la discusión presente los numerales i), ii), vii) y viii), los que en resumen dan cuenta de la proposición como una representación y a la descripción como la función que más interesa en el lenguaje.

A esta reconstrucción debemos sumarle algunas declaraciones de Abugattás que conforman el centro de esta primera parte de la discusión: el que la teoría del significado del TLP sea entendida como una teoría contemplativa que deba superarse por la teoría del uso. Según Abugattás, todas las teorías del significado anteriores a la teoría del uso tienen como rasgo común el de ser "contemplativas":

(...) En el sentido preciso que da Marx a esa palabra, para designar a las proposiciones filosóficas que formulan el problema del conocimiento en términos de la relación sujeto-objeto. En efecto, en los planteos que hemos presentado arriba, se trata, siempre, de esclarecer la relación entre significado y significante, concibiéndola como un hecho estático, petrificado (Abugattás 1972, p. 5). 
En principio, y tomando en cuenta siempre la consideración de la teoría del significado del TLP como una teoría contemplativa, resulta relevante el hecho de que para Abugattás una proposición como una figura no solo represente un estado de cosas sino que los reproduzca. Un asunto que también me interesa rescatar es que, tal y como presenta a las teorías contemplativas, Abugattás no parece considerar al problema filosófico del conocimiento sino solo desde tales teorías contemplativas. Es decir, Abugattás equipara incorrectamente las expresiones "reproducir" con "representar" desde su lectura reductiva de toda gnoseología como una y solo una teoría contemplativa.

Las diferencias que quiero establecer de manera intuitiva son las siguientes: la expresión "reproducir" encierra ya la pretensión de que la "imagen" no solo sea tal, sino que además sea la realidad misma (como ocurre en el Cratilo, con la duplicación de mundos ${ }^{9}$ ), en la medida que hay una pretensión de exactitud y corrección cerradas, que procuran dar cuenta del mundo tal y cual es. Pero Wittgenstein no contempla esto, como queda claro en su exposición de la "malla" en el TLP (Wittgenstein 2001, 6.341). Las descripciones están sujetas a otros criterios, y de hecho, pueden ser varias las formas de describir y no solo una, y menos alguna con la pretensión de ser la única con una exactitud cerrada e incorregible. Por otro lado, "reproducir" entraña ya el equívoco de la "copia" de la realidad, como ocurre, esto sí, en las teorías contemplativas que Abugattás critica. "Representar", en cambio, tiene otro sentido, siempre que entendamos que una proposición es un signo a la manera de una "imagen" o "figura" que describe un estado de cosas, cuya corrección no depende de la figura por sí misma, sino de su pertenencia a un entramado proposicional constituido por un sistema del mundo. Además, según esta perspectiva, "representar" desde un tejido proposicional no pierde la dimensión constructiva y categorial del lenguaje como un medio para conocer la realidad, que presupone ya un compromiso, una manera de ver el mundo o lo que esperamos ver en él. Esto sí se pierde en el concepto "reproducir", que imaginaría un "dar cuenta" del mundo desde el mundo mismo, como ocurre en las teorías contemplativas. Por último, "representar" no sería equivalente a "reproducir" porque es posible que tengamos varias representaciones incluso simultáneamente ${ }^{10}$, mientras que en la idea de reproducir nos dejamos tentar por la creencia en una sola

9 En el Cratilo, Sócrates lleva al extremo la tesis naturalista respecto de la rectitud de las denominaciones por medio de la cual no existiría diferencias entre la imagen y aquello que reproduce. Lo que ocurre es que, si se trata de una imagen, ésta no debería reproducir todo lo que supuestamente representa, de lo contrario ya no serían la imagen y lo representado dos cosas diferentes sino una duplicación de realidad. Cf. Cratilo 432 b-d.

10 Este es el espíritu que encontramos también en las Philosophische Bemerkungen: "Cada vez que digo que en lugar de tal y cual representación se podría también usar esta otra, damos un paso adelante hacia el objetivo de atrapar la esencia de lo que es representado” (Wittgenstein 1997, I, 1). 
imagen que reproduciría, como algo fijo, la esencia de aquello que queremos reproducir.

Para desarrollar mis siguientes observaciones procuraré señalar brevemente aquella tercera observación que, como indiqué al inicio, serviría de eje a toda mi argumentación. La misma tiene que ver con la pregunta en torno a cuál es la motivación central del TLP, qué es lo que intenta demostrar Wittgenstein en esta obra. Aunque dicha pregunta probablemente pueda contestarse de varias maneras, suscribiré una en particular que, a mi juicio, resulta plausible respecto al programa central del $T L P$ visto desde su teoría del significado como la forma general de la proposición: Wittgenstein refuta la tesis de Mauthner a propósito de la relación entre lenguaje y mundo. Con esto quiero insistir en que, como el mismo Abugattás señala respecto al método analítico, no hay una teoría que flote en el aire, sino que está comprometida con una concepción del mundo, y en el caso de la teoría del significado del TLP, comprometida con la comprensión de la relación entre lenguaje, mundo y conocimiento. Sin embargo, en su crítica a la teoría del significado como una teoría contemplativa Abugattás no atiende e ignora dicha concepción. Esta ontología y gnoseología están comprendidas en el intento por contravenir la tesis de Mauthner según la cual el lenguaje no proporciona ningún conocimiento del mundo.

La manera cómo establezco la relación entre Mauthner y Wittgenstein es a través del concepto de filosofía y lo que la filosofía debiera hacer. El punto coincidente es que para ambos la filosofía está comprometida con el análisis del lenguaje, pero la manera cómo entienden la naturaleza del lenguaje y sobre todo las consecuencias de su análisis son muy distintas en cada caso. Dice Wittgenstein en el TLP que "toda filosofía es "crítica linguística». (En todo caso, no en el sentido de Mauthner) (Wittgenstein 2001, 4.0031). ¿Pero cuál es ese sentido de Mauthner contra el cual, según estamos argumentando, redacta Wittgenstein el TLP? Fritz Mauthner se considera el creador de la crítica linguiística como una nueva disciplina ${ }^{11}$ cuyo aporte filosófico consistiría en que el problema del conocimiento debe pasar primero por la crítica misma de la naturaleza del lenguaje.

Yo confío en haber escogido un justo camino para una filosofía. Para una crítica del conocimiento, la cual es crítica del lenguaje (Mauthner 2001, p. 21).

La consecuencia de esta nueva forma de concebir la teoría del conocimiento es que solo sabremos si es posible conocer el mundo si, analizando la esencia

\footnotetext{
11 "Ahora bien; me quiere parecer que este mi propio trabajo y también mi problema no fueron completamente infructuosos y que, por lo menos, de él ha salido, para agregarse a las otras disciplinas en las que no soy profesional, una disciplina más. Crítica del lenguaje (...) Y si yo fuera ambicioso, expresaría el deseo de ser considerado como experto en esta nueva disciplina que yo he creado" (Mauthner 2001, p. 24).
}

LETRAS 81 (116), 2010 
del lenguaje, caemos en la cuenta que éste nos lo permite. Pero esa es una posibilidad que Mauthner ha negado, y que conforma la tesis principal como resultado de su crítica linguiística.

Al querer presentar y desarrollar el pensamiento mío, de que el conocimiento del mundo por medio del lenguaje es imposible, que una ciencia del mundo no existe y que el lenguaje es un chisme inútil para el conocimiento, lo quise hacer de un modo concluido y convincente, claro y vivo, no lógica y palabreramente (Mauthner 2001, pp. 23-24).

Ocurre que, según la crítica linguiística de Mauthner el lenguaje en su entraña es algo que resulta más valioso para el poeta que para el pensador. Su argumento es éste: Desde la crítica linguiística como teoría del conocimiento observamos que el lenguaje es esencialmente metafórico y por ello más bien un medio artístico para la poesía y no un instrumento de conocimiento. Por tal razón, no podemos usar el lenguaje para conocer el mundo ${ }^{12}$.

La idea de que el lenguaje sea ineficaz para cualquier esfuerzo mayor hacia el conocimiento nos debería hacer más precavidos en su uso (Mauthner 2001, p. 103).

Como lo he venido indicando, lo que sostengo es que la teoría del significado del TLP cobra sentido si se lee como una respuesta a aquella imposibilidad cognitiva desde el lenguaje planteada por Mauthner, asunto que en la crítica de Abugattás nunca aparece, presentándonos a dicha teoría del significado "flotando en el aire". Volveré entonces al examen de la crítica de Abugattás a la teoría del significado en el TLP como una teoría contemplativa más valiéndome del marco propuesto.

Haciendo una evaluación general de la tesis de Abugattás desde sus críticas a las teorías contemplativas del significado, podemos advertir una clara tendencia antirrepresentacional, que discute el rol de las descripciones como algo fundamental, y enfatiza el papel de la praxis y la utilidad. En este punto de vista pragmático, Abugattás se enfrenta a los enfoques esencialistas y reductivos, y revalida el plano de la acción. Lo interesante de la tesis de Abugattás es que está en la línea de los que discuten las teorías únicas y omniabarcativas herederas de los supuestos metafísicos de la filosofía moderna. Sin embargo, en su argumentación comete el error de restarle peso al lenguaje descriptivo desde una finalidad gnoseológica, como si toda relación entre lenguaje y conocimiento ocurriera únicamente desde teorías contemplativas.

Pero hay un nuevo elemento de la argumentación de Abugattás en contra de las teorías contemplativas que me interesa comentar. Se trata de la inclusión de los hablantes del lenguaje ordinario.

\footnotetext{
12 Complementariamente, si el lenguaje no puede servirnos para conocer el mundo, nunca podremos conocer nada: "Aquel que quiera hacer una crítica linguiística seria y radical, será conducido por sus estudios a una inexorable ignorancia" (Mauthner 2001, p. 26).
} 
Según Abugattás, no debe sorprendernos que en una teoría contemplativa como la del TLP "la única función relevante del lenguaje" sea la función descriptiva,

Como si el único fin que persiguen los hablantes fuese la "contemplación”,

la "reproducción", de la realidad circundante (Abugattás 1972, p. 6).

Lo que observamos es que Abugattás agrega de contrabando la afirmación respecto de los fines de los hablantes. Ciertamente Wittgenstein en el TLP no piensa en los hablantes ni en sus intereses cuando señala una teoría "contemplativa", sino en un discurso proposicional constituido por la ciencia natural con el fin de describir estados de cosas del mundo, atendiendo al problema de cómo el lenguaje puede servir para este fin. En ningún momento Wittgenstein está pensando en los fines e intereses de los hablantes comunes, que se moverían en el lenguaje ordinario para la mayoría de sus fines. Abugattás confunde estos planos y, sobre todo, en su objetivo de convencernos de abandonar la teoría del significado del $T L P$, insiste en que el lenguaje ordinario resulta más importante en nuestra vidas, y que no hay una relación descriptiva entre alguna proposición del lenguaje ordinario y algún hecho del mundo. Dice Abugattás:

(...) Ya hemos visto que la función del lenguaje no es puramente descriptiva, esto es, no a toda proposición del lenguaje ordinario le corresponde un hecho (...) estas formas del lenguaje ordinario que en la teoría contemplativa del Tractatus habían sido arbitrariamente descalificadas, cumplen en nuestra vida una función tanto o más importante que las oraciones descriptivas (Abugattás 1972, p. 10).

La importancia del lenguaje ordinario radicaría en que usamos el lenguaje más bien para hacer cosas que para contemplarlas. Este es el argumento pragmático con que Abugattás evaluaría la conveniencia de la teoría del uso sobre la teoría figurativa.

Y es que Wittgenstein vio, certeramente, que los intereses reales de los hablantes no son tanto "contemplativos" como "prácticos". El lenguaje empezaba a ser concebido como un "instrumento", como una herramienta que alcanza su razón de ser en la "praxis". Lo que interesa al hablante no es solo ni primordialmente "hablar" sobre la realidad, sino actuar en ella y sobre ella (Abugattás 1972, p. 6)

Según Abugattás, cuando Wittgenstein supera el TLP a través de la teoría del uso, logra "enfrentar el fenómeno del lenguaje directamente, a saber, como comúnmente se muestra y funciona” (Abugattás 1972, p. 6). El texto que a continuación agrega Abugattás resulta clave porque explicita el sentido de su crítica:

Es por ello que la exposición de la teoría del uso empieza con una crítica a las tesis del Tractatus que se basan, fundamentalmente, en lo que, después del viraje, debe ser tenido por un prejuicio. $Y$ es que, 
normalmente, el lenguaje que juega un rol en la vida de las personas no es tanto el lenguaje formal, sino el llamado "lenguaje común", que parecía antes tan despreciable y confuso (Abugattás 1972, p. 7).

Cuando se dice que el lenguaje común es confuso, propiamente deber entenderse que esto era visto así para los fines representacionales en que podemos usar el lenguaje para conocer el mundo, no en el sentido de ser "confuso" en sí mismo. El lenguaje ordinario no sería útil en ese sentido, pero no se le niega funcionalidad en otras dimensiones extra cognitivas en términos cientí$\operatorname{ficos}^{13}$. Lo único que quiere decir esto es que el lenguaje ordinario como tal no sirve para hacer ciencia, pero por supuesto, quién negaría que sea útil en la vida diaria.

Como vemos, en la lectura de Abugattás respecto del cambio de la teoría figurativa por la teoría del uso, pareciera haber un antes y un después sin ningún punto de encuentro, como una vuelta de página, como alguien que antes miraba así y ahora mira asá, cuando lo que ocurre es que ambas maneras de entender el lenguaje corresponden a intereses diferentes y programas diferentes. El asunto se puede graficar más o menos así. Es como si diseñáramos una casa según un modelo y luego decidimos edificarla, con sus puertas y ventanas, pero cuando queremos ingresar los muebles notamos que algunos son muy grandes y no pasan a través de la puerta, y tenemos que dejarlos en la calle, pero están allí. La preocupación por la ciencia y por lo que podemos decir en el lenguaje desde la ciencia obligaba a considerar condiciones muy exigentes de claridad y precisión, razón por la que era inevitable dejar al lenguaje ordinario, con todo lo cómodamente confuso que podía ser, esperando afuera.

De manera semejante a como ocurrió con Descartes y su duda metódica, ésta servía a un propósito, que no era sino la edificación de las ciencias desde bases seguras y confiables, para lo que solo podíamos fiarnos de rasgos universales y permanentes a través de una mente atenta. Sin embargo, Descartes no puede llevar al extremo esta duda más allá de una preocupación científica. Es decir, que para el plano de la acción diaria y el sentido común, Descartes, como cualquiera de nosotros, se valía de lo que veían sus ojos y camina sin

\footnotetext{
13 Lo que quiere decir esto es que el lenguaje ordinario tiene otros objetivos no representacionales. Así lo entiende Wittgenstein en el TLP: "El lenguaje ordinario es una parte del organismo humano y no menos complicado que éste. Es humanamente imposible extraer de él inmediatamente la lógica del lenguaje. El lenguaje disfraza el pensamiento. Y de un modo tal, en efecto, que de la forma externa del ropaje no puede deducirse la forma del pensamiento disfrazado; porque la forma externa del ropaje está constituida de cara a objetivos (Zwecken) totalmente distintos que el de permitir reconocer la forma del cuerpo" (Wittgenstein 2001, 4.002). Asimismo, el pollachôs legesthai aristotélico ocurriría en el plano del lenguaje ordinario: "En el lenguaje ordinario sucede con singular frecuencia que la misma palabra designe de modo y manera distintos (...) Así la palabra "es" se presenta como cópula, como signo de igualdad y como expresión de existencia (Wittgenstein 2001, 3.323).
} 
dudar mientras atravesaba una calleja en Ámsterdam y conversaba con Hélène. No tenía, de hecho, ningún sentido, llevar esta duda sobre la información sensorial y exigencia de certeza al plano en que nos movemos diariamente, y en el que, como también hacía Descartes, nos comunicamos por el lenguaje ordinario. De la misma forma, la preocupación de Wittgenstein está comprometida con una búsqueda y un programa para las ciencias, y como hemos tratado de explicar, su teoría figurativa del lenguaje intenta responder a estas exigencias.

Como hemos venido insistiendo en nuestra argumentación, parte de la estrategia de Abugattás por convencernos de las virtudes de la teoría del uso consiste en señalar las debilidades de la teoría del significado del TLP que deben ser superadas. En particular su argumento gira en torno a la siguiente idea: En el TLP la teoría "contemplativa" del significado nos conduce a asumir que hay una única función del lenguaje que es la función descriptiva. Además, dicha teoría "contemplativa" del TLP descuida los intereses y los fines de los hablantes, aspecto que es central en la teoría del uso, el mismo que le permite enfocar el fenómeno del lenguaje directamente. Por tal razón, reconocer las ventajas de la teoría del uso implica abandonar la teoría "contemplativa" del $T L P$, puesto que la propia evolución de Wittgenstein puede interpretarse en ese sentido, es decir, como una superación del TLP. Ciertamente, nuestro objetivo no es aquí examinar las ventajas de la teoría del uso por sí mismas, o en relación a las teorías contemplativas, sino evaluar hasta qué punto la aceptación de esta teoría del uso implica negar la apuesta presentada en el TLP. Probablemente costaría defender la teoría figurativa como tal según aparece en el TLP frente a la teoría del uso, pero sí podríamos sentirnos aún comprometidos con el programa general del TLP tal y como se ha presentado aquí: como una apuesta por entender el mundo desde el lenguaje más allá de las metáforas. Podemos discutir respecto de las teorías contemplativas el que se funden en una gnoseología representacional que aun divide el mundo en sujetos y objetos, incluso, con el fin de reproducirlos, pero no la pretensión de querer conocer la realidad como algo legítimo.

Hay una última consideración que merece ser incluida en esta parte como un elemento más de la crítica de Abugattás a la teoría del significado en el TLP. Abugattás considera que la apuesta por la construcción de un lenguaje ideal en que a cada término le corresponde un solo significado resulta ahora vacía e inútil, y para mostrar cómo ha ocurrido este cambio en el propio Wittgenstein, cita un pasaje de las $P h$. B.:

Qué extraño fuera que la lógica se ocupase de una lengua "ideal”, y no de la nuestra. Pues, ¿qué expresaría este lenguaje ideal? Seguramente eso que expresamos comúnmente en nuestro lenguaje; entonces, la lógica debe investigarlo a él (...) El análisis lógico es el análisis de algo que 
Álvaro Revolledo NovoA

tenemos, no de algo que no tenemos. Es en consecuencia, el análisis de

las oraciones tal y como ellas son. (Wittgenstein 1997, I, 3).

Lo que muestra el pasaje citado es que, entre los cambios ocurridos desde el TLP a las $P h$. B., se ha abandonado la empresa de construir un lenguaje ideal a favor del análisis del lenguaje ordinario. Pero isignifica eso que se ha abandonado también la búsqueda de relacionar el lenguaje con el mundo desde una perspectiva cognitiva? El argumento de Abugattás es reductivo, en la medida que vincula directamente el interés de construir un lenguaje ideal con la iniciativa de conocer el mundo desde el lenguaje, con lo que, al abandonarse la apuesta por un lenguaje ideal, debería seguirse aparentemente el abandono de dicha iniciativa. Pero iexiste tal relación de necesidad, que al anular la primera, se sigue la anulación de la segunda? Tal parece que no es así, pues la iniciativa se mantiene intacta, aun incluso si dejamos un lenguaje ideal y nos valemos del análisis del lenguaje ordinario, o si podemos combinar el uso de un lenguaje formal con métodos de análisis del lenguaje ordinario.

\section{La teoría del uso en las Philosophische Bemerkungen}

En el apartado anterior se discutió algunos aspectos referentes a la crítica de Abugattás a la teoría del significado en el TLP. Básicamente, la apuesta de Abugattás por la teoría del uso lo obligaba a abandonar la teoría figurativa como una mera teoría contemplativa, pero sobre todo porque, según Abugattás, en ella Wittgenstein aun está pensando en la esencia del lenguaje y por ello concluye que ésta tiene que ver con una función única o dominante de naturaleza descriptiva. Restaría decir, de acuerdo a nuestro examen, que el planteamiento de Wittgenstein no es tanto cuál es la esencia del lenguaje, sino la esencia del conocimiento, y que solo al considerarla de manera expresamente representacional a través de la posibilidad que el lenguaje represente estados de cosas del mundo derivaba en una pregunta por la esencia del lenguaje, a saber, la forma en que el lenguaje en tanto conformado por signos servía específicamente para representar o figurar los hechos del mundo. Es nuevamente su preocupación gnoseológica la que lo lleva a considerar una sola forma o una forma dominante del lenguaje con el fin de conocer el mundo.

Pero lo que queremos discutir a continuación es un asunto ligeramente distinto, o en todo caso, complementario al primero, toda vez que gira en torno a la teoría del uso. Lo que queremos saber aquí es si, como afirma Abugattás, en las Philosophische Bemerkungen aparece ya una teoría del uso como parte de la superación wittgensteiniana de la teoría figurativa. Nuestra respuesta es que tal afirmación es falsa, cuando menos, de acuerdo a las coordenadas que presentaremos a continuación. 
Ciertamente Abugattás no desarrolla una argumentación que justifique la presencia de una teoría del uso en las $P h$. $B$, sino que lo asume como algo dado, siempre teniendo en cuenta que para Abugattás la teoría del uso constituye una superación de la teoría figurativa que califica de contemplativa. El único pasaje en el que Abugattás se refiere a esto es el siguiente:

Esta más que concisa presentación que acabamos de hacer de las teorías tradicionales del significado, tiene como única finalidad la de servir como marco de referencia a la exposición de la "teoría del uso", presentada por Wittgenstein en todas sus obras posteriores al Tractatus, desde las Philosophische Bemerkungen (1930), donde está esbozada, hasta sus notas sobre algunas tesis de Moore, publicadas con el nombre de Über Gewissheit (1949-51) (Sobre la Certeza), escritas poco antes de la muerte del autor (Abugattás 1972, p. 5).

Hay dos cosas aquí afirmadas: que después del TLP Wittgenstein apuesta por la teoría del uso, y que dicha teoría está al menos esbozada en las Ph. B. Lo que hay que preguntarnos es si la primera afirmación quiere decir que la teoría del uso después del TLP reemplaza totalmente a la teoría figurativa, y si esto ocurre ya en las $P h$. B. De acuerdo a la crítica de Abugattás a la teoría figurativa como una teoría contemplativa, todo parece indicar que es eso lo que quiere decir. Si ese es el caso, entonces, la afirmación de Abugattás, según la cual la teoría del uso aparece en las $P h$. B., es falsa. Para exponer mi argumentación comenzaré citando un pasaje de la tesis de Abugattás en que se condensa el sentido de dicha teoría del uso ${ }^{14}$.

El vuelco hacia la teoría del uso, decíamos, se produjo cuando Wittgenstein reconoció que el lenguaje no es sino un instrumento más maleable que los demás. Esto es, el lenguaje sirve, esencialmente, para hacer cosas, para actuar. El lenguaje es, por lo tanto, una forma de vivir o, como Wittgenstein prefiere decirlo, una "forma de vida" (eine Lebens form) (Abugattás 1972, p. 10).

Según Abugattás, la novedad de la teoría del uso es su dependencia de "las formas de vida" para saber qué hacemos efectivamente con el lenguaje. Esto no podría significar sino que, desde la teoría del uso, hay ahora una relativa prioridad del lenguaje ordinario para hacer cosas y ya no, como ocurría con las teorías contemplativas, la prioridad de un lenguaje figurativo con el compromiso de representar estados de cosas del mundo. De esa forma,

\footnotetext{
14 Por obvias razones, no puedo detenerme aquí en la exposición de Abugattás sobre la teoría del uso, pero principalmente porque no constituye una condición necesaria para la comprensión de mis observaciones presentes, ya que basta recordar que la teoría del uso, como lo explica Abugattás, no está comprometida con la figuración del mundo sino solo con el uso del lenguaje como una forma de vida. Para Abugattás, el concepto wittgensteiniano de "forma de vida" es la categoría primordial de la teoría del uso (Cf. Abugattás 1972, p. 14).
}

LETRAS 81 (116), 2010 
bastará demostrar que aun en las $P h . B$. Wittgenstein está interesado en valerse del lenguaje con el fin de representar el mundo para que la afirmación de Abugattás, como dije anteriormente, sea falsa.

Las $P h$. B. son un conjunto diverso y voluminoso de comentarios respecto de varios tópicos que harían muy difícil la empresa de querer simplificarlos burdamente. Contrariamente a ello, me dedicaré a bosquejar las coincidencias que existen es esta obra con el TLP respecto de la teoría figurativa y, por supuesto, el interés por usar el lenguaje con fines cognitivos. Aunque no pueda señalar rápidamente las diferencias entre un texto y el otro sobre sus teorías del significado, lo que Abugattás simplifica en grado sumo ${ }^{15}$, aceptaré que hay una diferencia importante en esta última con la inclusión de los significados a partir del uso. Sin embargo, esto todavía no es la teoría del uso. Es más, contrariamente a lo que afirma Abugattás, el uso aquí es un aspecto que se ciñe aún a las proposiciones. De manera semejante al TLP pero con más detalles, la proposición (Bild) es un modelo y un patrón de medida que sirve para representar. Si hubiera una teoría del uso en las $P h$. B., ésta tendría que ver con el uso de proposiciones o sistemas proposicionales.

Solo en el contexto de una proposición tiene una palabra significado: eso es como decir que es solo cuando se le usa que una vara es una palanca. Solo la aplicación la convierte en palanca (Wittgenstein 1997, II, 14).

Algunos pasajes de las $P h$. B. se asemejan notablemente al espíritu del TLP, cuando se trata de afirmar la relación entre el lenguaje y la realidad desde la figuración proposicional.

La concordancia de una proposición con la realidad solo se parece a la concordancia de un retrato (Bild) con lo retratado (Wittgenstein 1997, II, 19).

No se puede comparar un retrato con la realidad a menos que se le pueda contraponer como un instrumento de medición. Se debe poder sobreponer la proposición a la realidad (Wittgenstein 1997, IV, 43).

Lo que de momento es relevante para nuestra argumentación, es que en las $P h$. B.se mantiene intacta la creencia en la conexión entre el lenguaje y la realidad, y, es más, se insiste en que el lenguaje sirve específicamente para representar al mundo. Esto es casi como preguntarnos, ¿si el lenguaje no sirve para representar al mundo, para qué sirve? El pasaje que mejor muestra este asunto es el siguiente:

Una y otra vez se hace el intento por usar el lenguaje para limitar el mundo y ponerlo de relieve -pero eso no puede hacerse. La autoevidencia del mundo se expresa precisamente en el hecho mismo de que el lenguaje puede referirse a él y solo a él refiere. Porque dado que el lenguaje deriva su modo de significar

15 Ciertamente, señalar estas diferencias como algo de fondo, no constituye un objetivo de la tesis de Abugattás. 
solo de su significado, del mundo, no es concebible ningún lenguaje que no represente a este mundo (Wittgenstein 1997, V, 47).

El lenguaje es esencialmente representacional, y no hay aquí ni formas de vida ni otros fines del lenguaje que no sea la representación. No es verdad, entonces, que esté presente aquí el esbozo de una teoría del uso, entendida como una superación de la teoría figurativa, pues, al contario, podemos afirmar que hay entre las $P h . B$. y el $T L P$ una continuidad a propósito de la figuración que nos permite una lectura consistente de ambas obras. No es cierto, tampoco, que después del TLP Wittgenstein tenga un "vuelco" hacia dicha teoría del uso, y menos aun, como un abandono de la preocupación que, según hemos querido argumentar aquí, constituye la motivación del TLP: cómo el lenguaje puede permitirnos el conocimiento del mundo.

\section{Reflexión final: Abugattás y la nueva filosofía analítica}

Hemos revisado en este ensayo algunas de las afirmaciones respecto de la obra de Wittgenstein escritas por Abugattás, pero hemos dejado en el camino muchas otras, tanto o más valiosas. La tesis de Abugattás exige una mayor aproximación y discusión con sus planteamientos y sus observaciones, pues, como lo indicamos al inicio, es una investigación que expone agudeza crítica y una bella retórica, pero además, aquel valor que Abugattás tenía en alta estima, la imaginación filosófica, la misma que era una constante junto con la sagacidad filosófica que conocimos en su autor.

Quiero concluir este breve ensayo haciendo hincapié en un aspecto que me parece importante en la perspectiva de Abugattás. El interés que hemos visto en nuestro filósofo por el método analítico se ajusta a una nueva manera de entender el propio movimiento de la filosofía analítica. Con esta observación final, me animo a considerar los aportes de Abugattás en la misma dirección de aquellos filósofos que, como él, abrazaron un interés por una analítica renovada, principalmente, porque se veían libres de ciertos prejuicios positivistas contra la metafísica. Abugattás considera que muchos filósofos sufren de una "castración del pensamiento filosófico".

A juzgar por la vergüenza con que se rechaza el tratamiento de los problemas que se llama "metafísicos" (Abugattás 1972, p. 44).

Abugattás, igual que Strawson o Tugendhat, concibe una filosofía analítica que no teme en incluir a las preocupaciones metafísicas como parte de sus investigaciones y análisis, razón por la que comprende una reformulación de la propia metafísica en contra de una metafísica tradicional ${ }^{16}$. Para Abugattás, el

16 En palabras de Tugendhat, "Solo cuando el análisis del lenguaje tenga en cuenta las preguntas que subyacen a las palabras de la metafísica y que las han motivado, puede llegar a ser efecti- 
propio Wittgenstein tuvo como punto de partida de su pensamiento el problema de la metafísica, aspecto que caracterizaría a todo filosofar auténtico (Cf. Abugattás 1972, p. 46).

Y es que la filosofía, despojada del pathos religioso o, si se quiere, metafísico, que constantemente lo ha animado, no puede diferenciarse de las ingeniosas triquiñuelas de un saltimbanqui (Abugattás 1972, p. 45).

Como parte de la tradición analítica sanmarquina, Juan Abugattás es, sin duda, el representante más conspicuo de esta nueva perspectiva analítica, por mérito propio.

\section{Referencias bibliográficas}

ABUGATTÁS, J. (1972). El concepto de análisis en la Segunda Filosofía de L. Wittgenstein (Tesis de bachiller). Lima, UNMSM.

BALLÓN VARGAS, J.C. (1983). Wittgenstein y la teoría del conocimiento (Tesis de licenciatura). Lima, UNMSM.

MAUTHNER, F. (2001). Contribuciones a una crítica del lenguaje. Barcelona, Editorial Herder.

PLATÓN (2002). Cratilo o Del lenguaje. Madrid, Ediciones Trotta.

REVOLLEDO NOVOA, A. (2009). Menos Platón y más Darwin. Lima, Editorial Mantaro.

SALAZAR BONDY, A. (1969). "Metafísica y antimetafísica en Wittgenstein", en Diálogos. Abril-junio. N. ${ }^{\circ}$ VI/15; Puerto Rico, pp. 75-99.

SALAZAR BONDY, A. (1971). "El problema del valor en el primer Wittgenstein. A propósito de Tractatus Logico-Philosophicus, 6.4-6.421”, en Para una filosofía del valor. Santiago de Chile, Editorial Universitaria.

TUGENDHAT, E. (1997). Ser, verdad, acción. Ensayos filosóficos. Barcelona, Editorial Gedisa. WITTGENSTEIN, L. (1997a). Observaciones Filosóficas. Edición Bilingüe. Traducción de Alejandro Tomasini Bassols. México, Universidad Nacional Autónoma de México.

WITTGENSTEIN, L. (2001). Tractatus Logico-Philosophicus. Edición Bilinguie. Traducción de Jacobo Muñoz e Isidoro Reguera. Madrid, Alianza Editorial.

vamente productiva la crítica a ellas, productiva tanto para las criticadas como para los críticos (Tugendhat 1997, p. 26.) 